\title{
François Valentijn Antara etika dan estetika
}

\author{
R.Z. LEIRISSA
}

\begin{abstract}
A controversial book on the history of the VOC in the seventeenth century was written by François Valentijn, a preacher in the payroll of the Dutch East India Company (VOC). The book (eight volumes), published in 1724-1726, was known by its popular title Oud en Nieuw Oost-Indiën. Most of the materials in the book were pirated from other sources without acknowledging their authors as is the proper practice of historiography. But as to its style, a number of Dutch writers appreciated its esthetic qualities. Beside that, the book is indeed useful to historians today because some of the materials pirated in the book have now been lost forever.

KEYWORDS

François Valentijn, VOC, Ambon, Cornelia Snaats, Rumphius, Beekman, Maria Dermoût.
\end{abstract}

Tidak mudah menulis sejarah VOC (Vereenigde Oost-Indische Compagnie, Serikat Dagang Hindia Timur) pada masanya (1602-1799). Para penguasa VOC (de Heeren Zeventien, tujuh belas anggota dewan direktur VOC) melarang para pegawai atau mantan pegawainya untuk menulis apa saja yang berkenaan dengan kegiatan badan dagang itu. Larangan itu dapat dipahami karena rahasia perusahaan tidak boleh jatuh ke tangan pedagang lain, dan larangan semacam itu sedikit-banyaknya masih berlaku bagi dunia usaha di masa kini.

Sekalipun ada larangan tersebut, dari waktu ke waktu ada beberapa pegawai atau mantan pegawai VOC yang memberanikan diri menulis sejarah VOC. Dua di antaranya yang terkenal sekarang adalah Georgius Everhardus Rumphius (1627-1702) dan François Valentijn (1666-1727). Rumphius adalah seorang pegawai VOC keturunan Jerman (nama aslinya adalah Georg Everard Rumphius). Dengan status sebagai tentara VOC ia tiba di Ambon pada tahun 1653, tetapi dialihkan sebagai pegawai sipil. Dengan izin VOC sekitar awal tahun 1669 ia mulai mempelajari secara sistematis fauna dan flora di pulau Ambon. Hasilnya adalah sebuah naskah yang berjudul Het Amboinsche

R.Z. LEIRISSA adalah Guru Besar dan pengajar pada Departemen Sejarah, Fakultas Ilmu Pengetahuan Budaya, Universitas Indonesia. Karya tulisnya yang terakhir antara lain: Kekuatan Ketiga dalam Perjuangan Kemerdekaan Indonesia (2006, Pustaka Sejarah). 
Kruidboek yang lebih dikenal sebagai Herbarium Amboinensis. Karya yang diselesaikan pada tahun 1690 itu dikerjakan dengan bantuan beberapa asisten karena sejak tahun 1670 Rumphius telah menjadi buta (glaucoma) dan sebab itu pula ia dikenal dengan julukan "De blinde ziener" (si buta yang dapat melihat). Selain itu, Rumphius juga menulis tentang dunia binatang (zoologi) dengan judul D'Amboinsche Rariteitkamer. Sebuah naskah lain mengenai zoologi yang sekarang tidak ditemukan kembali adalah Het Ambonsche Dierboek.

Sekalipun lebih menaruh perhatian pada tanaman dan binatang, sebagai seorang ilmuwan Rumphius juga tertarik pada manusia. Dari tangannya muncul sebuah naskah sejarah Ambon. Namun, penerbitannya dilarang oleh VOC. Naskah itu baru diterbitkan pada tahun 1910 dengan judul “De Ambonsche historie, behelsende een kort verhaal der gedenkwaardigste geschiedenissen zo in vreede als oorlog voorgevallen sedert dat de Nederlandsche Oost Indische Comp. het besit in Amboina gehadt heeft" dalam Bijdragen tot de Taal-, Land-en Volkenkunde 64. Selain itu, ia juga menulis mengenai geografi sosial pulau Ambon; pada tahun 1983 diterbitkan di Jakarta (dengan suntingan Z.J. Manusama) oleh Arsip Nasional Republik Indonesia dan pada tahun 2002 di Utrecht diterbitkan oleh Landelijk Steunpunt Educatie Molukkers.

Pada tahun 1666 François Valentijn lahir, 39 tahun setelah Rumphius di Dordrecht Belanda. Setelah menamatkan pendidikannya dalam bidang teologi dan filsafat di Leiden dan Utrecht, ia dipekerjakan oleh VOC sebagai pendeta dengan tempat kedudukan di Ambon. Ia berada di Ambon antara tahun 1685 sampai tahun 1695 dan antara tahun 1706 dan tahun 1714. Dalam periode pertama di Ambon ia dekat dengan Rumphius, bahkan belajar bahasa Melayu dari ahli botani itu. Kemudian ia menikah dengan seorang janda kaya, yaitu Cornelia Snaats, janda dari teman dan pelindungnya yang kaya yang bernama Hendrik Snaats. Sebab itu ketika ia kembali ke Belanda pada tahun 1714 ia tidak perlu mencari pekerjaan tetap dan hanya aktif menulis (Beekman 1988: 55-95). Sekembali di Dordrecht, Belanda, selama sepuluh tahun ia menulis sebuah buku sejarah VOC monumental yang secara popular dikenal kemudian dengan nama Oud en Nieuw Oost-Indiën yang diterbitkan tahun 1724-1726.

Ada tiga perbedaan mencolok antara Rumphius dan Valentijn. Pertama, kalau Rumphius berdiam di Ambon sebagai seorang ahli botani selama sekitar 50 tahun dan meninggal di sana, maka Valentijn bertugas sebagai pendeta di pulau itu hanya sekitar dua belas tahun. Perbedaan pokok kedua adalah bahwa dalam sekian banyak naskah itu Rumphius hanya menulis mengenai pulau Ambon. Sebaliknya Valentijn, selain menulis mengenai Maluku (yang ditemukan pada beberapa bagian dari Oud en Nieuw Oost-Indiën) juga menulis mengenai wilayah-wilayah kegiatan VOC lainnya di Asia (di bagian lainnya). Perbedaan ketiga adalah bahwa sejak abad ketujuh belas hingga hari ini Rumphius tetap dihormati oleh kalangan ilmuwan internasional sebagai seorang yang berjasa bagi ilmu pengetahuan. Pada tahun 1681 ia mendapat penghargaan dari sebuah lembaga ilmiah, yaitu Academia Naturae 
Curiosorum dengan gelar Plinius Indicus (Sirks 1915). Sebaliknya Valentijn, yang bukunya memang laku keras di zamannya, mendapat penilaian yang negatif baik oleh para pejabat VOC maupun oleh para sejarawan Belanda. Semasa hidupnya ia tidak disenangi oleh para petinggi VOC, terutama Gubernur Jenderal Joan Maetsuycker yang memegang jabatan itu selama sekitar 50 tahun dan mengenal Valentijn. Para sejarawan Belanda dari bagian pertama abad kedua puluh menuduh Valentijn sebagai seorang yang tidak jujur dan yang menggunakan profesi kependetaannya untuk mencari kekayaan semata-mata karena kawin dengan janda kaya. Sejarawan F. de Haan (19101912) dalam tulisannya yang berjudul Priangan: de Preanger-Regentschappen onder het Nederlandsch Bestuur tot 1811 melontarkan tuduhan bahwa Valentijn adalah seorang plagiator. Kritik itu masih berkumandang dalam bagian kedua abad kedua puluh seperti nampak dalam tulisan E. M. Beekman dari Universitas Massachusetts. Bahkan Beekman (1988: 67) menuduh Valentijn sebagai seorang oportunis dan pencuri naskah orang lain yang diaku sebagai naskahnya, yaitu naskah terjemahan Injil dalam bahasa Melayu Rendah. Menurut Beekman, terjemahan Injil itu sesungguhnya dilakukan oleh Simon de Larges yang meninggal tahun 1677. Di kemudian hari naskah terjemahan itu jatuh ke tangan seorang pendeta lain yang kebetulan tinggal bersama Valentijn yang tiba di Ambon pada tahun 1685. Ketika pendeta itu meninggal pada tahun 1687, naskah terjemahan itu jatuh ke tangan Valentijn. Ketika kembali ke Hindia, pada tahun 1706 Valentijn menyerahkan naskah itu kepada para pejabat VOC. Namun, naskah itu ditolak karena "[...] mutu bahasa Melayunya yang tidak merata dan dugaan pemalsuan yang tidak pernah bisa dibantah oleh Valentijn" (Beekman 1988: 67). ${ }^{1}$ Naskah terjemahan Injil dari Valentijn itu hingga kini tidak pernah ditemukan kembali.

Biografi Valentijn dapat juga dibaca dalam karya yang ditulis oleh R.R.F. Habiboe (2004). ${ }^{2}$ Tampaknya Habiboe memiliki versi tersendiri mengenai karya dan pribadi Valentijn. Ada nada positif pada judul bukunya (Tot verheffing van mijne natie [...]) yang saya kira diambil dari keterangan Valentijn sendiri dalam bukunya di mana antara lain ia menyebutkan tujuan penulisan bukunya itu: "[...] untuk menerapkan segala yang saya miliki bagi kemajuan Bangsa saya [...]" (Beekman 1988: 71). ${ }^{3}$

\section{KaRYA VALENTIIN}

Karya monumental dari Valentijn, seperti yang telah disebut di atas, dikenal dengan judul singkatnya sebagai Oud en Nieuw Oost-Indiën. Judul lengkapnya adalah Oud en Nieuw Oost-Indiën, vervattende een naaukeurige en uitvoerige verhandelinge van Nederlands mogentheyd in die gewesten, benevens een wydlustige beschryvinge der Moluccos, Amboina, Banda, Timor en Solor, Java en alle de eylanden onder dezelve landbestieringen behoorende: het Nederlands comptoir op Suratte, en de levens der groote Mogols; als ook een keurlyke verhandeling van 't wezentlykste, dat men behoort te weten van Choromandel, Pegu, Arracan, Bengale, Mocha, Persien,

$1 \quad$ Kutipan terjemahan R. Z. Leirissa.

2 Sayang sekali tulisan Habiboe ini belum sempat saya pelajari dengan seksama.

3 Kutipan terjemahan R. Z. Leirissa. 
Malacca, Sumatra, Ceylon, Malabar, Celebes of Macassar, China, Japan, Tayouan of Formosa, Tonkin, Cambodia, Siam, Borneo, Bali, Kaap der Goede Hoop en van Mauritius (Dordrecht: Joannes van Braam; Amsterdam: Gerard onder de Linden, 1724-1726). Buku yang terbit dalam delapan volume ini terdiri dari lima bagian dengan ketebalan buku 5.144 halaman, dilengkapi dengan 79 buah peta dan 182 ilustrasi lainnya. Lima bagian itu adalah sebagai berikut: (I) berisi deskripsi mengenai Maluku Utara, Sulawesi Timur, dan pulau-pulau di sekitarnya, (II) berisi wilayah Ambon dan pulau-pulau sekitarnya seperti Seram, Buru, Nusalaut, Haruku, beserta diskripsi geografisnya, (III) berisi sejarah gereja dari wilayah-wilayah tersebut di atas, keterangan mengenai flora dan faunanya, dan disambung dengan deskripsi mengenai Banda, Timor, Sulawesi, Kalimantan, Bali, Tonking, Cina. Kamboja, dan Siam, (IV) berisi keterangan mengenai pulau Jawa, riwayat hidup para Gubernur Jenderal VOC dari tahun 1610. Kemudian menyusul sejarah pembentukan kota Batavia, lalu diikuti keterangan riwayat hidup dinasti Moghul di India, lalu Cina, Formosa (atau Tayouan), dan diakhiri dengan kisah pelayaran bolak-balik sebanyak empat kali Belanda-Hindia, (V) berisi deskripsi mengenai Koromandel dan bagian-bagian lain dari India, Persia, Malaka, Sri Lanka, Malabar, Jepang, Tanjung Harapan, dan pulau Mauritius.

Dari daftar pembagian isi itu dapat dipahami bahwa Valentijn tidak mengikuti suatu konsep yang jelas untuk menyusun bukunya, baik geografis maupun historis. Ketidakteraturan itu lebih jelas lagi dalam setiap bagian, umpamanya Sumatra diselipkan antara Malaka dan Sri Lanka. Sulawesi selain terdapat dalam bagian I juga terdapat dalam bagian III. Tongking (Vietnam Utara) diselipkan antara Jawa dan Bali, sedangkan India dibahas dalam tiga bagian. Uraian mengenai Jawa dan Sumatra hanya sepintas lalu dibandingkan dengan uraian mengenai Maluku Utara dan Ambon yang mencakup dua jilid penuh (jilid I dan jilid II)

Dari judul bukunya itu dapat disimpulkan bahwa Valentijn membagi sejarahnya dalam dua periode utama. Periode pertama adalah masa pra-VOC yang disebutnya sebagai Oud Oost-Indië dan masa VOC sebagai Nieuw OostIndië. Dua periode itu terpisah secara ketat dalam uraiannya dan tidak terjadi tumpang tindih. Sama sekali tidak ada upaya untuk menjelaskan bagaimana atau sampai di mana VOC mempengaruhi perkembangan masyarakat lokal yang berinteraksi dengannya. Teori-teori interaksi seperti itu memang tidak lazim dalam masa VOC karena menunggu perkembangan ilmu sejarah dalam abad kesembilan belas dan kedua puluh.

\section{ETIKA}

Sebagai seorang pendeta dan dengan latar belakang pendidikan filsafat dan teologi, dapat dipastikan bahwa Valentijn mempunyai pengetahuan dasar mengenai sejarah. Namun, apakah ia memiliki pengetahuan mengenai bagaimana menulis sejarah? Bagaimana orang Barat pada masa Valentijn menulis sejarah? Terobosan yang dipelopori oleh Leopold von Ranke (17951886) dalam bukunya yang diterbitkan di Leipzig pada tahun 1824 merupakan 
kritikan yang tajam mengenai cara penulisan sejarah di masa itu (Gilbert 1990: 12-14). Ranke menganjurkan para penulis sejarah untuk tidak hanya mengutip ulang buku-buku yang telah ditulis sebelumnya tetapi langsung menggunakan dokumen-dokumen otentik dengan cara yang kritis. Oleh karena itu, dapat dipastikan bahwa penggunaan dokumen otentik belum menjadi keharusan di masa itu. Metode itulah yang umumnya digunakan oleh Valentijn.

Kritikan yang dilontarkan oleh para sejarawan terhadap buku Valentijn tersebut adalah bahwa ia tidak jujur mengemukakan dari siapa atau dari buku siapa ia memperoleh keterangan untuk bukunya itu. Oleh sebab itu, ia dicap sebagai seorang yang tidak etis dan disebut sebagai plagiator.

Bagaimana sesungguhnya Valentijn bekerja? Ternyata di dalam bukunya itu di sana-sini ia menyebut bahwa ia menggunakan tulisan atau keterangan dari orang-orang tertentu. Secara khusus ia menyebut nama Rumphius yang dikenalnya di Ambon dan yang karya-karyanya, baik mengenai sejarah maupun mengenai flora, fauna, dan dunia binatang di Maluku, disadurnya dengan panjang lebar. Di beberapa tempat ia menulis bahwa ia juga memperoleh berbagai dokumen dari para pegawai VOC tertentu. Kemungkinan besar dokumen itu diterimanya ketika ia telah kembali di negeri Belanda (Gilberts 1990: 59-63).

Namun, mengenai Maluku, Batavia, dan sebagian dari pulau Jawa, nampaknya Valentijn juga menggunakan hasil observasinya sendiri ketika ia berada di tempat-tempat itu. Bahkan mengenai sejarah pra-VOC di Maluku (Oud Oost-Indië) ia menggunakan hasil wawancara. Ketika ia hendak menulis sejarah kerajaan-kerajaan di Maluku Utara (dalam jilid I) ia sempat mendatangi beberapa bangsawan Ternate yang sedang dipenjarakan di Ambon. Kepada mereka ia tunjukkan sebuah naskah lama mengenai sejarah Ternate yang ditulis dalam bahasa Ternate dengan menggunakan aksara Arab. Naskah itu diperolehnya dari seseorang di Luhu, pusat perdagangan Ternate di Seram. Ia meminta agar para tawanan itu menerjemahkan naskah itu baginya. Ada indikasi bahwa Valentijn mengenal berbagai naskah lama lainnya dari Maluku Utara yang kini sudah tidak ada lagi.

Selain itu, di Maluku Valentijn sempat juga mempelajari bahasa Melayu dari Rumphius, sekalipun hanya sekitar tiga bulan. Namun, istrinya, Cornelia Snaats, tampaknya sangat mahir dalam berbahasa Melayu itu, dan menjadi bantuan yang menentukan bagi Valentijn dalam menyusun khotbahnya dalam bahasa Melayu. Valentijn tampaknya juga menggunakan kamus bahasa Melayu yang disusun oleh Rumphius yang naskahnya hingga kini belum ditemukan kembali.

Kalau keterangan mengenai keadaan di Indonesia bisa diperolehnya dari pengalamannya sendiri serta para mantan pegawai VOC atau dengan cara mengutip Rumphius, bagaimana Valentijn memperoleh keterangan mengenai wilayah-wilayah Asia lain yang merupakan wilayah kegiatan VOC yang dicakup dalam bukunya itu? Bagaimana umpamanya Valentijn memperoleh sumber sejarah untuk mendeskripsikan sejarah di wilayah-wilayah Persia, 
India, Sri Lanka, Asia Tenggara, Cina, dan Jepang?

Menurut Beekman informasi mengenai Persia dan Koromandel diperoleh Valentijn dari tulisan dan buku dari seorang yang bernama Herbert de Jager yang mungkin lahir pada tahun 1636 dan meninggal di Batavia pada tahun 1694 (Beekman 1988: 67-70). De Jager adalah seorang ahli bahasa-bahasa Timur lulusan Universitas Leiden. Setelah lulus ia menjadi pegawai VOC dan mengenal, bahkan berkiriman surat dengan Rumphius di Ambon. Ia pernah bertugas sebagai penerjemah di Persia dan Koromandel, pertama kalinya selama lima belas tahun antara tahun 1665 hingga tahun 1680, dan kedua kalinya antara tahun 1682 dan tahun 1687 . Tidak lama setelah meninggal di Batavia pada tahun 1694 berkas-berkasnya dilelang. Kebetulan pada tahun 1694 Valentijn juga berada di Batavia dalam perjalanan pulang ke Belanda. Namun, dalam bukunya itu Valentijn menulis bahwa ia tidak bertemu dengan De Jager karena, tulisnya, ahli bahasa itu meninggal di Isfahan (Persia). Namun, baik De Haan maupun Beekman yakin bahwa Valentijn berbohong untuk menutup kenyataan bahwa dia memang menggunakan bahan-bahan dari De Jager untuk menceritakan keadaan di Persia dan Koromandel.

Pekerjaan rumah bagi para ahli historiografi adalah menjawab pertanyaan bagaimana Valentijn memperoleh sumber sejarah untuk menulis mengenai India, Sri Lanka, Asia Tenggara, Cina, dan Jepang. Selain itu, seluruh buku Valentijn itu masih harus dikaji ulang untuk menentukan keabsahan dari keterangan-keterangannya.

\section{ESTETIKA}

Betapapun juga Oud en Nieuw Oost-Indiën itu memang bermanfaat bagi ilmu sejarah. Sumber sejarah yang digunakannya memang belum ditelurusi secara tuntas, tetapi jelas ada keterangan-keterangan yang hanya bisa diperoleh dari buku itu saja. Namun, harus dikatakan juga bahwa sebagai historiografi buku Valentijn tersebut sama sekali tidak etis.

Namun, sekalipun dari segi sejarah karya Valentijn itu dikatakan tidak etis, dari segi sastra ada nilai estetikanya. Menurut Beekman, tidak kurang dari seorang Edward du Perron, kritikus sastra modern itu, yang menilai bahwa Valentijn dapat dikategorikan sebagai "[...] a remarkably fine storyteller in prose [...]" (Beekman 1988: 79).

Buku Valentijn itu juga merupakan sumber inspirasi bagi Maria Dermoût (1888-1962). Novelis Belanda itu banyak menggunakan keterangan dari buku Valentijn itu untuk menulis novel-novelnya yang mengandung cerita-cerita yang berlangsung di Ambon dan sekitarnya, seperti De tienduizend dingen, atau cerpen-cerpen yang dikumpulkan dalam antologinya yang berjudul Verzamelde werken seperti "Koning Baboe en de veertig jongelingen", "De boom des levens", dan "De goede slang" (Beekman 1988: 80, 93). Mengenai pengalamannya membaca buku Valentijn itu, novelis Belanda itu menulis: "Saya sering membaca buku itu, terutama bagian-bagian mengenai 'Deskripsi tentang Maluku' dan 'Masalah-masalah Maluku' tetapi kemudian menyingkirkannya karena saya terganggu oleh begitu banyak kesombongan, 
kemunafikan, bajakan dari Rumphius, namun kemudian saya kembali membacanya lagi karena ia menaruh perhatian yang begitu baik dan karena ia pandai bercerita" (Beekman 1988: 80). ${ }^{4}$

\section{PENUTUP}

Oud en Nieuw Oost-Indiën adalah judul singkat dari karya monumental François Valentijn. Buku yang terbit dalam delapan volume (1724-1726) memuat deskripsi wilayah-wilayah kegiatan VOC di Asia dan juga khususnya di Nusantara. Cara penyajian materi isi tidak berurut baik secara geografis maupun historis. Namun, isi buku ini jelas terbagi dalam dua periode, yaitu periode sebelum VOC (Oud Oost-Indië) dan masa VOC (Nieuw Oost-Indië). Walaupun banyak dikritik karena dianggap tidak etis, pada praktiknya kandungan isi buku ini tetap banyak dimanfaatkan baik oleh peneliti sejarah maupun sastra. Sumber dan karya asal informasi bajakan itu pada kenyataannya sudah tidak dapat ditemukan lagi sekarang ini. Tidaklah mengherankan jika buku yang kontroversial itu dianggap memiliki nilai estetika, selain juga berkat penceritaannya yang menarik. Seperti pernyataan seorang kritikus sastra, Edward du Perron, bahwa François Valentijn adalah seorang pencerita yang ulung.

\section{DAFTAR PUSTAKA}

Beekman, E.M. 1988. "François Valentijn”, di dalam: Beekman (red.), Fugitive dreams: an anthology of Dutch colonial literature, hlm. 55-95. Amherst: University of Massachusetts Press.

De Haan, F. 1910-1912. Priangan: de Preanger-Regentschappen onder het Nederlandsch Bestuur tot 1811. 's-Gravenhage: Nijhoff.

Gilbert, Felix. 1990. History: politics or culture? Reflections on Ranke and Burckhardt. Princeton: Princeton University Press.

Habiboe, R.R.F. 2004. Tot verheffing van mijne natie; Het leven en werk van François Valentijn (1666-1727). Franeker: Van Wijnen.

Sirks, M.J. 1915. Indisch natuuronderzoek: een beknopte geschiedenis van de beoefening der natuurwetenschappen in de Nederlandse koloniën. Amsterdam: Koloniaal Instituut.

Rumphius, G. E. 1983. Ambonsche landbeschrijving. Suntingan Z. J. Manusama. Jakarta: Arsip Nasional Republik Indonesia. (Penerbitan Sumber-sumber Sejarah/ANRI No. 14).

Rumphius, G.E. 2002. De Ambonse eilanden onder de VOC: zoals opgetekend in de Ambonsche landbeschrijoing. Utrecht: Landelijk Steunpunt Educatie Molukkers.

Valentijn, François. 1724-26. Oud en Nieuw Oost-Indiën, [...]. Dordrecht: Joannes van Braam; Amsterdam; Gerard onder de Linden. 